\title{
Ier METROCOL - Apadrinhamento do Laboratório de Química e Biomedicina do Instituto Nacional de Metrologia da Colômbia
}

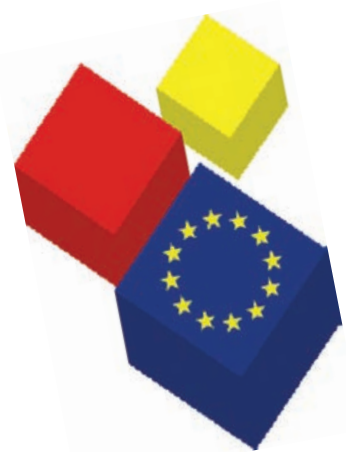

A Metrologia é Fundamental para a Inovação

Diretora do Departamento Nacional Colombiano de Planeamento

A convite da Comissão Organizadora do Primeiro Encontro Internacional de Metrologia da Colômbia, jer METROCOL, que teve lugar em Bogotá, de 13 a 15 de agosto de 2012, e que contou com a presença do Secretário de Estado para o Desenvolvimento Industrial, do Ministério de Comércio, Indústria e Turismo do país, bem como de representantes ao mais alto nível das infraestruturas metrológicas regionais e mundiais, coube-me a honra de proferir a Lição de Abertura, "Impacto da Metrologia Química na
Investigação Académica e no Desenvolvimento Industrial".

Sob o mote "Prosperidade para todos", o evento assinalou a recente criação do Instituto Nacional de Metrologia (INM), fruto de uma estrutura anterior de Laboratórios de Metrologia, versando as vertentes de Metrologia Científica e Metrologia Industrial. Além de áreas clássicas de Metrologia Física, há também um investimento arrojado na área da Química e Biomedicina, desde já equipada com um laboratório primário e secundário de medidas de condutibilidade elétrica e de $\mathrm{pH}$ para a produção e certificação de soluções tampão de $\mathrm{pH}$, de que assinalamos a inauguração. Com equipamento adquirido com financiamento do Projeto DCI-ALA/2007/19-005, de Assistência Técnica da Comissão Europeia na perspetiva da promoção e expansão das trocas comerciais, o Laboratório, dirigido por Luis Alfredo Chavarro, conta com o contributo de dois jovens investigadores, em fase de formação, empenhados no sucesso da missão de que são atores. Após várias horas de uma produtiva sessão de trabalho conjunto estava-me reservada a agradável surpresa de ser convidada para Madrinha do Laboratório. Ciente das responsabilidades, assumi o compromisso com gosto.

Além da constituição de competências centralizadas no INM, o Programa Nacional de Desenvolvimento da Metrologia compreende também o estabelecimento de uma Rede Nacional de Metrologia assente no levantamento das capacidades nacionais de laboratórios.

A Coordenadora e grande impulsionadora do Projeto é a eminente metrologista brasileira, Vera Ponçano, com quem tenho o prazer de partilhar experiências e conhecimentos desde a altura da minha presidência da EURACHEM, coincidente com a sua presidência do CITAC.

Maria Filomena Camões (mfcamoes@fc.ul.pt)

Coordenadora do Mestrado Europeu em Ciência da Medição em Química Presidente da Divisão de Química Analítica da IUPAC

\section{Falecimento do Professor Manuel Ribeiro da Silva}

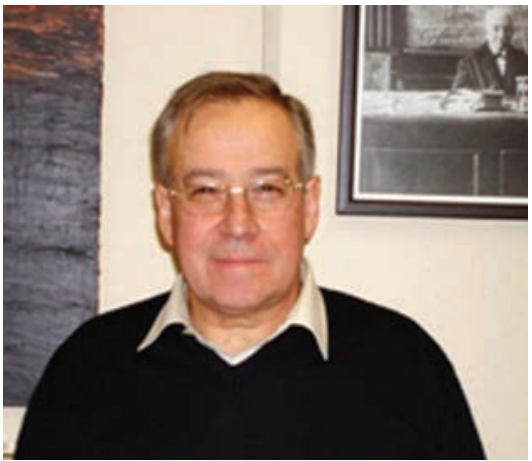

Foi com grande pesar que a comunidade de químicos portugueses soube do faleciemnto do Professor Manuel Ribeiro da Silva, no dia 29 de novembro de 2012.

Manuel Ribeiro da Silva, nascido a 30 de setembro de 1940, distinto sócio da SPQ, onde desempenhou vários cargos, incluindo o de Presidente, era atualmente Professor Emérito da Faculdade de Ciências da Universidade do Porto. O Professor Ribeiro da Silva dedicou a sua vida inteiramente ao ensino e à investigação, sendo autor de um vasto conjunto de publicações científicas nas mais conceituadas revistas internacionais de Química.

Licenciou-se em Engenharia Químico-Industrial (FEUP) em 1964/65 e doutorou-se em Química na Universidade de Surrey, Inglaterra, em janeiro de 1974, após ter cumprido o Serviço Militar na Marinha. De regresso à Universidade do Porto, iniciou uma frutuosa atividade de investigação no domínio da Termoquímica, no Depar- tamento de Química da Faculdade de Ciências, onde conseguiu estabelecer condições de trabalho assinaláveis para um novo grupo de investigação, numeroso e de assinalável produtividade. Este grupo publicou até hoje mais de quatro centenas de artigos de elevada qualidade.

Recebeu várias distinções nacionais e internacionais, sendo de realçar o Prémio Ferreira da Silva em 2002. A Química nacional perdeu um dos seus expoentes, que se destacou, não só pela investigação, mas também pela dedicação ao ensino e à comunidade científica.

bquimica@ipb.pt www.spq.pt 